\title{
Metformin: an old but still the best treatment for type 2 diabetes
}

\author{
Lilian Beatriz Aguayo Rojas* and Marilia Brito Gomes
}

\begin{abstract}
The management of T2DM requires aggressive treatment to achieve glycemic and cardiovascular risk factor goals. In this setting, metformin, an old and widely accepted first line agent, stands out not only for its antihyperglycemic properties but also for its effects beyond glycemic control such as improvements in endothelial dysfunction, hemostasis and oxidative stress, insulin resistance, lipid profiles, and fat redistribution. These properties may have contributed to the decrease of adverse cardiovascular outcomes otherwise not attributable to metformin's mere antihyperglycemic effects. Several other classes of oral antidiabetic agents have been recently launched, introducing the need to evaluate the role of metformin as initial therapy and in combination with these newer drugs. There is increasing evidence from in vivo and in vitro studies supporting its anti-proliferative role in cancer and possibly a neuroprotective effect. Metformin's negligible risk of hypoglycemia in monotherapy and few drug interactions of clinical relevance give this drug a high safety profile. The tolerability of metformin may be improved by using an appropiate dose titration, starting with low doses, so that side-effects can be minimized or by switching to an extended release form. We reviewed the role of metformin in the treatment of patients with type 2 diabetes and describe the additional benefits beyond its glycemic effect. We also discuss its potential role for a variety of insulin resistant and pre-diabetic states, obesity, metabolic abnormalities associated with HIV disease, gestational diabetes, cancer, and neuroprotection.
\end{abstract}

Keywords: Metformin, Diabetes mellitus, Insulin, Resistance

\section{Introduction}

The discovery of metformin began with the synthesis of galegine-like compounds derived from Gallega officinalis, a plant traditionally employed in Europe as a drug for diabetes treatment for centuries [1]. In 1950, Stern et al. discovered the clinical usefulness of metformin while working in Paris. They observed that the dose-response of metformin was related to its glucose lowering capacity and that metformin toxicity also displayed a wide security margin [1].

Metformin acts primarily at the liver by reducing glucose output and, secondarily, by augmenting glucose uptake in the peripheral tissues, chiefly muscle. These effects are mediated by the activation of an upstream kinase, liver kinase B1 (LKB-1), which in turn regulates the downstream kinase adenosine monophosphatase

\footnotetext{
*Correspondence: lilian_aguayo@yahoo.com; mariliabgomes@gmail.com Department of Medicine, Diabetes Unit, State University of Rio de Janeiro, Av 28 setembro 77, Rio de Janeiro CEP20555-030, Brazil
}

co-activator, transducer of regulated CREB protein 2 (TORC2), resulting in its inactivation which consequently downregulates transcriptional events that promote synthesis of gluconeogenic enzymes [2]. Inhibition of mitochondrial respiration has also been proposed to contribute to the reduction of gluconeogenesis since it reduces the energy supply required for this process [3].

Metformin's efficacy, security profile, benefic cardiovascular and metabolic effects, and its capacity to be associated with other antidiabetic agents makes this drug the first glucose lowering agent of choice when treating patients with type 2 diabetes mellitus (TDM2).

\section{Metformin and pre-diabetes}

In 2000, an estimated 171 million people in the world had diabetes, and the numbers are projected to double by 2030 . Interventions to prevent type 2 diabetes, therefore, have an important role in future health policies. Developing countries are expected to shoulder the majority of the burden of diabetes [4]. One of the main

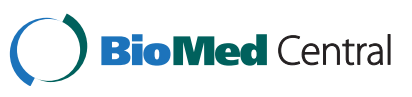


contributing factors to this burden is the Western lifestyle which promotes obesity and sedentarism [5].

Impaired glucose tolerance (IGT) and impaired fasting glucose (IFG) statuses are associated with increased and varying risk of developing type 2 diabetes mellitus. IGT has been associated with an increased risk of cardiovascular events and may determine an increased mortality risk. The association of IFG with cardiovascular events, however, has not been well established [6].

When lifestyle interventions fail or are not feasible, pharmacological therapy may be an important resource to prevent type 2 diabetes. Several different drug classes have been studied for this purpose.

In their systematic review, Gillies et al. found that lifestyle and pharmacological interventions reduced the rate of progression to type 2 diabetes in people with IGT and that these interventions seem to be as effective as pharmacological treatment. Although compliance was high, treatment effect was not sustained after treatment was stopped. According to the results of their meta-analysis, lifestyle interventions may be more important in those with higher mean baseline body mass index BMI [5].

The best evidence for a potential role for metformin in the prevention of type 2 diabetes comes from The Diabetes Prevention Program (DPP) trial. Lifestyle intervention and metformin reduced diabetes incidence by $58 \%$ and $31 \%$, respectively, when compared with placebo [7].

At the end of the DPP study, patients were observed for a one to two week wash out period. Diabetes incidence increased from 25.2 to $30.6 \%$ in the metformin group and from 33.4 to $36.7 \%$ in the placebo group. Even after including the wash out period in the overall analysis, metformin still significantly decreased diabetes incidence (risk ratio $0.75, \mathrm{p}=0.005$ ) compared with placebo [8]. These data suggest that, at least in the short-term, metformin may help delay the onset of diabetes. The benefits of metformin were primarily observed in patients $<60$ years old (RR 0.66) and in patients with a BMI greater than $35 \mathrm{~kg} / \mathrm{m}^{2}$ (RR 0.47) [7] (Table 1).

Metformin significantly reduced the risk of developing diabetes in an Indian population of subjects with IGT. The relative risk reduction was $28.5 \%$ with lifestyle modification $(\mathrm{p}=0.018), 26.4 \%$ with metformin $(\mathrm{p}=$
$0.029)$, and $28.2 \%$ with lifestyle modification plus metformin $(\mathrm{p}=0.022)$, as compared with the control group [9] (Table 1).

In a Chinese study, subjects with IGT randomly assigned to receive either low-dose metformin $(750 \mathrm{mg} /$ day) or acarbose (150 mg/day) in addition to lifestyle intervention were compared to a control group that only received life style intervention. Treatment with metformin or acarbose produced large, significant, and similar risk reductions for new onset of $\mathrm{T} 2 \mathrm{DM}$ of $77 \%$ and $88 \%$, respectively; these reductions were larger than that of lifestyle intervention alone [10].

The persistence of the long-term effects obtained through DPP interventions were evaluated at an additional follow-up after a median of 5.7 years. Individuals were divided in 3 groups: lifestyle, metformin, and placebo. Diabetes incidence rates were similar between treatment groups: 5.9 per 100 person-years (5.1-6.8) for lifestyle, 4.9 (4.2-5.7) for metformin, and 5.6 (4.8-6.5) for placebo. Diabetes incidence 10 years since DPP randomization was reduced by $34 \%$ and $18 \%$ in the lifestyle and metformin group, respectively [11] (Table 1).

The prevalence of pre-diabetes as well as the progression rate to diabetes may differ between different populations, making the application of results from certain studies of different ethnical groups inappropriate. IGT is highly prevalent in native Asian Indians. This population has several unique features such as a young age of diabetes onset and lower BMI along with high rates of insulin resistance and lower thresholds for diabetic risk factors [12]. Chinese individuals have a lower prevalence of diabetes and are less insulin resistant than Indians, so the results of the Chinese study may not be applicable to Asian Indian individuals [13].

In a meta-analysis of randomized controlled trials, Salpeter et al. reported a reduction of $40 \%$ in the incidence of new-onset diabetes with an absolute risk reduction of $6 \%$ (95\% CI, 4-8) during a mean trial duration of 1.8 years [14].

Lily and Godwin reported a decreased rate of conversion from pre-diabetes to diabetes in individuals with IGT or IFG in their systematic review and meta-analysis of randomized controlled trials. This effect was seen at both a higher metformin dosage (850 mg twice daily)

Table 1 Effectiveness of metformin in diabetes prevention of patients with impaired glucose tolerance

\begin{tabular}{lcccccc}
\hline Study & Randomized & Country & N & $\begin{array}{c}\text { Duration } \\
\text { years }\end{array}$ & $\begin{array}{c}\text { Mean change in risk } \\
\text { MET (\%) }\end{array}$ & $\begin{array}{c}\text { Mean change in risk } \\
\text { LSM (\%) }\end{array}$ \\
\hline DPP [7] & yes & USA & 3234 & 3 & $-31 \%$ & $-58 \%$ \\
IDPP [9] & yes & India & 522 & 3 & $-26.4 \%$ & $-28.2 \%$ \\
Yang et al. [10] & yes & China & 321 & 2.5 & $-77 \%$ & - \\
DPPOS [11] & yes & USA & 2766 & 5.7 & $-18 \%$ & $-34 \%$ \\
\hline
\end{tabular}

DPP: Diabetes Prevention Program, DPP: Indian Diabetes Prevention Program, DPPOS: Diabetes Prevention Outcome Study, MET: Metformin, LSM: Lifestyle modification. 
and lower metformin dosage (250 mg twice or 3 times daily) in people of varied ethnicity [15].

\section{Metformin in the management of adult diabetic patients} Current guidelines from the American Diabetes Association/European Association for the Study of Diabetes (ADA/EASD) and the American Association of Clinical Endocrinologists/American College of Endocrinology (AACE/ACE) recommend early initiation of metformin as a first-line drug for monotherapy and combination therapy for patients with T2DM. This recommendation is based primarily on metformin's glucose-lowering effects, relatively low cost, and generally low level of side effects, including the absence of weight gain $[16,17]$.

Metformin's first-line position was strengthened by the United Kingdom Prospective Diabetes Study (UKPDS) observation that the metformin-treated group had risk reductions of $32 \%(\mathrm{p}=0.002)$ for any diabetes-related endpoint, $42 \%$ for diabetes-related death $(\mathrm{p}=0.017)$, and $36 \%$ for all-cause mortality $(\mathrm{p}=0.011)$ compared with the control group. The UKPDS demonstrated that metformin is as effective as sulfonylurea in controlling blood glucose levels of obese patients with type 2 diabetes mellitus [18]. Metformin has been also been shown to be effective in normal weight patients [19].

\section{Metformin in combination therapy}

Although monotherapy with an oral hypoglycemic agent is often initially effective, glycemic control deteriorates in most patients which requires the addition of a second agent. Currently, marketed oral therapies are associated with high secondary failure rates [20]. Combinations of metformin and insulin secretagogue can reduce $\mathrm{HbA1c}$ between $1.5 \%$ to $2.2 \%$ in patients sub-optimally controlled by diet and exercise [21].

The optimal second-line drug when metformin monotherapy fails is not clear. All noninsulin antidiabetic drugs when added to maximal metformin therapy are associated with similar $\mathrm{HbA1c}$ reduction but with varying degrees of weight gain and hypoglycemia risk. A meta-analysis of 27 randomized trials showed that thiazolidinediones, sulfonylureas, and glinides were associated with weight gain; glucagon-like peptide-1 analogs, glucosidase inhibitors, and dipeptidyl peptidase-4 inhibitors were associated with weight loss or no weight change. Sulfonylureas and glinides were associated with higher rates of hypoglycemia than with placebo. When combined with metformin, sulfonylureas and alphaglucosidase inhibitors show a similar efficacy on HbA1c [22].

\section{Metformin and sulfonylureas}

The combination of metformin and sulfonylurea (SU) is one of the most commonly used and can attain a greater reduction in HbA1c (0.8-1.5\%) than either drug alone
$[23,24]$. The glimepiride/metformin combination results in a lower HbA1c concentration and fewer hypoglycemic events when compared to the glibenclamide/metformin combination [25]. The use of metformin was associated with reduced all-cause mortality and reduced cardiovascular mortality. Metformin and sulfonylurea combination therapy was also associated with reduced all-cause mortality [26].

Epidemiological investigations suggest that patients on SUs have a higher cardiovascular disease event rate than those on metformin. Patients who started SUs first and added metformin also had higher rates of cardiovascular disease events compared with those who started metformin first and added SUs. These investigations are potentially affected by unmeasured confounding variables [27].

\section{Metformin and insulin}

Metformin as added to insulin-based regimens has been shown to improve glycemic control, limit changes in body weight, reduce hypoglycemia incidence, and to reduce insulin requirements (sparing effect), allowing a $15-25 \%$ reduction in total insulin dosage $[28,29]$.

The addition of metformin to insulin therapy in type 1 diabetes is also associated with reductions in insulindose requirement and HbA1c levels [30,31].

\section{Metformin and thiazolinediones}

The addition of rosiglitazone to metformin in a 24-week randomized, double-blind, parallel-group study significantly decreased HbA1c concentration and improved insulin sensitivity and HOMA $ß$ cell function [32]. However, in spite of preventing diabetes incidence, the natural course of declining insulin resistance may not be modified by a low dose of the metformin-rosiglitazone combination [33].

The ADOPT study (A Diabetes Outcome Progression Trial) assessed the efficacy of rosiglitazone, as compared to metformin or glibenclamide, in maintaining long-term glycemic control in patients with recently diagnosed type 2 diabetes. Rosiglitazone was associated with more weight gain, edema, and greater durability of glycemic control; metformin was associated with a higher incidence of gastrointestinal events and glibenclamide with a higher risk of hypoglycaemia. [34].

\section{Metformin and glifozins}

Dapagliflozin, a highly selective inhibitor of SGLT2, has demonstrated efficacy, alone or in combination with metformin, in reducing hyperglycemia in patients with type 2 diabetes [35,36]. Studies are in development for assessing the safety and efficacy of this combination.

\section{Metformin and a glicosidase inhibitor}

Acarbose reduces the bioavailability of metformin [37]. However, it has been reported that the association of 
acarbose to metformin in sub-optimally controlled patients reduced HbA1c by about $0.8-1.0 \%$ [38].

\section{Metformin and incretin-based therapies}

DDPIV prolongs the duration of active glucagon-like peptide 1 (GLP-1) by inhibiting DPPIV peptidase, an enzyme which cleaves the active form of the peptide. This action results in an improvement of insulin secretion as a physiological response to feeding. The mechanism of DPPIV inhibitors is complementary to that of metformin which improves insulin sensitivity and reduces hepatic glucose production, making this combination very useful for achieving adequate glycemic control [39]. Metformin has also been found to increase plasma GLP-1 levels, probably by either direct inhibition of DPPIV or by increased secretion, leading to reduced food intake and weight loss [40].

Saxagliptin added to metformin led to clinically and statistically significant reductions in HbA1c from baseline versus metformin/placebo in a 24-week randomized, double-blind, placebo-controlled trial. Saxagliptin at doses of 2.5, 5, and $10 \mathrm{mg}$ plus metformin decreased A1 by $0.59 \%, 0.69 \%$, and $0.58 \%$, respectively, in comparison to an increase in the metformin plus placebo group $(+0.13 \%) ; \mathrm{p}<0.0001$ for all comparisons [41].

A meta-analysis of 21 studies examined incretin-based therapy as an add-on to metformin in patients with T2DM for 16-30 weeks; 7 studies used a short-acting GLP-1 receptor agonist (exenatide BID), 7 used longer acting GLP-1 receptor agonists (liraglutide or exenatide LAR), and 14 examined DPP-IV inhibitors. Long-acting GLP-1 receptor agonists reduced $\mathrm{HbA1c}$ and fasting glucose levels to a greater extent than the other therapies [42].

\section{Metformin and pregnancy}

Metformin is known to cross the placenta and concerns regarding potential adverse effects on both the mother and the fetus have limited its use in pregnancy [43]. The use of metformin during pregnancy is still a matter of controversy.

Two meta-analyses of observational studies, one of women using metformin and/or sulfonylureas and one of women using metformin alone during the first trimester, did not show an increase in congenital malformations or neonatal deaths $[44,45]$.

The Metformin in Gestational Diabetes (MiG) trial, found no significant difference in the composite fetal outcome (composite of neonatal hypoglycemia, respiratory distress, need for phototherapy, birth trauma, 5-minute Apgar score $<7$, or prematurity) between metformin and insulin. Women assigned to metformin had more preterm births and less weight gain compared to those in the insulin group [46]. Another randomized trial also found similar results [47].
Results of the MiG TOFU reported that infants of diabetic mothers exposed to metformin in utero and examined at 2 years of age may present a reduction in insulin resistance, probably related to an increase in subcutaneous fat [48].

Longer follow-up studies will be required to determine metformin's impact on the development of obesity and metabolic syndrome in offspring.

\section{Metformin use in childhood and adolescence}

Type 2 diabetes mellitus has dramatically increased in children and adolescents worldwide to the extent that has been labeled an epidemic [49]. Before 1990, it was a rare condition in the pediatric population; by 1999, the incidence varied from $8 \%$ to $45 \%$, depending on geographic location, and was disproportionally represented among minority groups [50]. There are few studies of metformin use in the pediatric population. Most of them are of short duration and heterogeneous designs.

The beneficial role of metformin in young patients with type 2 diabetes has been demonstrated in a randomized, controlled trial which showed a significant decrease in fasting blood glucose, HbAlc, weight, and total cholesterol. The most frequently reported adverse events were abdominal pain, diarrhea, nausea/vomiting, and headaches. There were no cases of clinical hypoglycemia, lactic acidosis, or clinically significant changes in physical examinations [51]. When compared to glimepiride (1-8 $\mathrm{mg}$ once daily), metformin (500-1000 mg twice daily) lowered HbA1c to $<7 \%$, similar to glimepiride, but was associated with significantly less weight gain. A total of $42.4 \%$ and $48.1 \%$ of subjects in the glimepiride and metformin groups, respectively, in the intent-to-treat population achieved $\mathrm{A} 1 \mathrm{C}$ levels of $<7.0 \%$ at week 24 [52].

There is some evidence that suggests improvement in metabolic control of poorly controlled adolescents with type 1 diabetes when metformin is added to insulin therapy. Metformin has been shown to reduce insulin dose requirement (5.7-10.1 U/day), HbA1c (0.6-0.9\%), weight $(1.7-6.0 \mathrm{~kg})$, and total cholesterol $(0.3-0.41 \mathrm{mmol} / \mathrm{l})$ [30]. A previous review showed similar results in HbA1 reduction and insulin requirement, however no improvements in insulin sensitivity, body composition, or serum lipids were documented [31].

Metformin indications for management of obesity, insulin resistance, and non-alcoholic fatty liver in children and adolescents

Insulin resistance in obese children and adolescents should be appropriately and aggressively addressed once it is linked to known cardiovascular risks such as IGT, T2DM, dyslipidemia, and hypertension [53,54]. Nonalcoholic fatty (NAFLD) disease, a frequent cause of chronic liver disease in obese adults, is also associated 
with a higher risk of developing diabetes and of progression to fibrosis and cirrhosis [55] with an increased relative risk of cardiovascular events or death [56]. The true prevalence of NAFLD in children is underestimated. The prevalence of steatosis in obese children was estimated to be $38 \%$ in a large retrospective autopsy study [57].

Currently, the best supported therapy for NAFLD is gradual weight loss through exercise and nutritional support [58]. Metformin is associated with short-term weight loss, improvement of insulin sensitivity, and decreased visceral fat [59]. A reduction in ALT, GGT, and fatty liver incidence and severity has also been described with metformin use [60].

Metformin has been used increasingly in obese children with hyperinsulinemia although there are no strong evidence-based studies supporting its use for this clinical condition. A moderate improvement in body muscular index (BMI) and insulin sensitivity has been reported with the use of metformin [61,62]. Heart rate recovery (HRR) may also improve due to improved parasympathetic tone, paralleling improvements in BMI, insulin levels, and insulin sensitivity [61]. HRR has been considered a predictor of mortality and cardiovascular disease in otherwise healthy subjects [63]. A poor HRR has also been linked to insulin resistance [64] and to a higher risk for developing T2DM [65].

Metformin may not be as effective as behavioral interventions in reducing BMI and when compared with drugs that are licensed for obesity, its effects are moderate [66].

\section{Effects of metformin on vascular protection Effects on cardiovascular mortality}

Diabetic patients are at high risk of cardiovascular events, particularly of coronary heart disease by about 3 -fold $[67,68]$. It has been stated that type 2 diabetic patients without a previous history of myocardial infarction have the same risk of coronary artery disease (CAD) as non-diabetic subjects with a history of myocardial infarction [69]. This has led the National Cholesterol Education Program to consider diabetes as a coronary heart disease risk equivalent [70]. Although there is no doubt that there is an increased risk of CAD events in diabetic patients, there is still some uncertainty as to whether the cardiovascular risk conferred by diabetes is truly equivalent to that of a previous myocardial infarction [71].

In 1980, Scambato et al. reported that, in a 3-year observational study of 310 patients with ischaemic cardiomyopathy, patients treated with metformin had reduced rates of re-infarction, occurrence of angina pectoris, acute coronary events other than acute myocardial infarction, and death in patients [72]. The largest effect was seen in re-infarction rates; a post hoc analysis showed that this effect was significant $(\mathrm{p}=0.003)$. After this study, the UKPDS, the largest randomized clinical trial in the newly-diagnosed type 2 diabetic population largely free of prior major vascular events, randomly assigned treatment with metformin to a subgroup of overweight individuals ( $>120 \%$ of ideal body weight). In 1990, another subgroup of patients $(n=537)$, who were receiving the maximum allowed dosage of sulfonylurea, were randomized either to continue sulfonylurea therapy or to allow an early addition of metformin [18].

Metformin provided greater protection against the development of macrovascular complications than would be expected from its effects upon glycemic control alone. It had statistically significant reductions in the risk of all-cause mortality, diabetes-related mortality $(p=$ $0.017)$, and any end-point related to diabetes $(p=0.002)$, but not in myocardial infarction $(\mathrm{p}=0.052)$ [18]. The UKPDS pos-trial reported significant and persistent risk reductions for any diabetes-related end point $(21 \%, \mathrm{p}=$ $0.01)$, myocardial infarction $(33 \%, \mathrm{p}=0.005)$, and death from any cause $(27 \%, \mathrm{p}=0.002)$ [73].

Following UKPDS, other studies have reported significant improvement of all-cause mortality and cardiovascular mortality (Table 2). A retrospective analysis of patients databases in Saskatchewan, Canada reported significant reductions for all-cause mortality and cardiovascular mortality of $40 \%$ and $36 \%$, respectively [26]. The PRESTO trial showed significant reductions of any clinical event (28\%), myocardial infarction (69\%), and all-cause mortality (61\%) [74]. The HOME trial reported a decreased risk of developing macrovascular disease [75]. In non-diabetic subjects with normal coronary arteriography but also with two consecutive positive (ST depression $>1 \mathrm{~mm}$ ) exercise tolerance test, an 8-week period on metformin improved maximal ST-segment depression, Duke score, and chest pain incidence compared with placebo [76]. A recent meta-analysis suggested that the cardiovascular effects of metformin could be smaller than had been hypothesized on the basis of the UKPDS; however, its results must be interpreted with caution given the low number of randomized controlled trials included [77].

\section{Metformin and heart failure}

The risk of developing cardiac heart failure (CHF) in diabetic individuals nearly doubles as the population ages [77]. DM and hyperglycemia are strongly implicated as a cause for the progression from asymptomatic left ventricular dysfunction to symptomatic $\mathrm{HF}$, increased hospitalizations for HF, and an overall increased mortality risk in patients with chronic HF [78]. Despite all its benefits, metformin is contraindicated in patients with heart failure due to the potential risk of developing lactic acidosis, a rare but potentially fatal metabolic condition resulting from severe tissue hypoperfusion [79]. The US Food and Drug Administration removed the heart failure 
Table 2 Metformin effects on vasculoprotection

\begin{tabular}{|c|c|c|c|}
\hline Study & Design & Duration & Key findings \\
\hline UKPDS 33 [18] & Prospective & $10 \mathrm{yr}$ & $\begin{array}{l}\text { Significant reduction in all-cause mortality, diabetes related mortality, and any end-point related to } \\
\text { diabetes. }\end{array}$ \\
\hline Sgambato et al. [72] & Retrospective & $3 \mathrm{yr}$ & Trend towards reduction in angina symptoms $(p=0.051)$. Significant lower re-infarction rates. \\
\hline Johnson et al. [24] & Retrospective & $9 \mathrm{yr}$ & Reduction of all-cause mortality and of cardiovascular mortality \\
\hline Kao et al. [74] & Prospective & $2 \mathrm{yr}$ & Significant risk reduction for any clinical event, myocardial infarction and all-cause mortality \\
\hline Jadhav et al. [76] & Prospective & 8 weeks & Improved maximal ST depression, Duke score, and chest pain incidence \\
\hline Kooy et al. [75] & Prospective & $4,3 \mathrm{yr}$ & Reduction of the risk of developing macrovascular disease \\
\hline
\end{tabular}

contraindication from the packaging of metformin although a strong warning for the cautious use of metformin in this population still exists [80].

Several retrospective studies in patients with $\mathrm{CHF}$ and diabetes reported lower risk of death from any cause [81-83], lower hospital readmissions for $\mathrm{CHF}$ [81], and hospitalizations for any cause $[81,82]$. A recent review concluded that $\mathrm{CHF}$ could not be considered an absolute contraindication for metformin use and also suggest its protective effect in reducing the incidence of CHF and mortality in T2DM [83]. This protective effect may due to AMPK activation and decrease in cardiac fibrosis [83].

In a prospective 4-year study, 393 metformin-treated patients with elevated serum creatinine between 1.5$2.5 \mathrm{mg} / \mathrm{dL}$ and coronary artery disease, CHF, or chronic obstructive pulmonary disease (COPD) were randomized into two groups. One group continued metformin therapy while the other was instructed to discontinue metformin. Patients with CHF had either New York Heart Association (NYHA) Class III or Class IV CHF and were receiving diuretic and vasodilatation drugs. There were no differences between groups in all-cause mortality, cardiovascular mortality, rate of myocardial infarction, or rate of cardiovascular events [84].

Patients with DM and advanced, systolic HF $(\mathrm{n}=401)$ were divided into 2 groups based on the presence or absence of metformin therapy. The cohort had a mean age of $56 \pm 11$ years and left ventricular ejection fraction (LVEF) of $24 \pm 7 \%$ with $42 \%$ and $45 \%$ being NYHA III and NYHA IV, respectively. Twenty-five percent $(\mathrm{n}=99)$ were treated with metformin therapy. Metformin-treated patients had a higher BMI, lower creatinine, and were less often on insulin. One-year survival in metformintreated and non-metformin-treated patients was 91\% and $76 \%$, respectively $(p=0.007)$. After a multivariate adjustment for demographics, cardiac function, renal function, and HF medications, metformin therapy was associated with a non-significant trend of improved survival [85].

Many different mechanisms, beyond glycemic control, have been implicated in vascular protection induced by metformin such as improvements in the inflammatory pathway [86], coagulation [87], oxidative stress and glycation [88-92], endothelial dysfunction [88-90], haemostasis [88,91-93], insulin resistance improvement [94], lipid profiles $[95,96]$, and fat redistribution $[97,98]$. Some of these mechanisms are described below.

\section{Beyond glycemic control}

The UKPDS recruited patients with newly diagnosed type 2 diabetes and demonstrated that tight glycemic control has beneficial effects on microvascular end points. However, it failed to show improvements in macrovascular outcomes. The improved cardiovascular disease (CVD) risk in overweight diabetic patients treated with metformin was attributed to its effects extending beyond glycemic control [18].

\section{Effects on the inflammatory pathway}

The benefits of metformin on macrovascular complications of diabetes, separate from its conventional hypoglycemic effects, may be partially explained by actions beyond glycemic control, particularly by actions associated with inflammatory and atherothrombotic processes [86]. Metformin can act as an inhibitor of pro-inflammatory responses through direct inhibition of NF-kB by blocking the PI3KAkt pathway. This effect may partially explain the apparent clinical reduction of cardiovascular events not fully attributable to metformin's anti-hyperglycemic action [86].

Some studies also point to a modest effect on inflammatory markers in subjects with IGT in T2DM [87] while others have found no effect at all [88].

\section{Effects on oxidative stress}

Oxidative stress is believed to contribute to a wide range of clinical conditions such as inflammation, ischaemiareperfusion injury, diabetes, atherosclerosis, neurodegeneration, and tumor formation [99].

Metformin has antioxidant properties which are not fully characterized. It reduces reactive oxygen species (ROS) by inhibiting mitochondrial respiration [100] and decreases advanced glycosylation end product (AGE) indirectly through reduction of hyperglycemia and directly through an insulin-dependent mechanism [101]. 
There is some evidence that metformin also has a beneficial effect on some components of the antioxidant defense system. It can upregulate uncoupled proteins 2 (UCP2) in adipose tissue [102] and can also cause an increase in reduced glutathione [100].

Metformin has been proposed to cause a mild and transient inhibition of mitochondrial complex I which decreases ATP levels and activates AMPK-dependent catabolic pathways [100], increasing lipolysis and $B$-oxidation in white adipose tissue [102] and reducing neoglucogenesis [2]. The resultant reduction in triglycerides and glucose levels could decrease metylglyoxal (MG) production through lipoxidation and glycoxidation, respectively [99,101].

Recently a study described a putative mechanism relating metformin action and inhibition of oxidative stress, inflammatory, and proapoptotic markers [103]. In this study, treatment of bovine capillary endothelial cells incubated in hyperglycemic medium with metformin was able to decrease the activity of NF-kB and others intracellular proteins related to cellular metabolic memory. The authors suggested that this action could be mediated by histone deacetylase sirtuin 1 (SIRT-1), a multifunctional protein involved in many intracellular pathways related to metabolism, stress response, cell cycle, and aging [103].

\section{Effects on endothelial function}

Type 2 diabetes is associated with a progressive and generalized impairment of endothelial function that affects the regulation of vasomotor tone, leucocyte adhesion, hemostasis, and fibrinolysis. These effects are probably direct and not related to decreases in hyperglycemia [88].

Contradictory effects of metformin on endothelial function have been described, however $[89,90]$. Mather et al. reported that metformin has no effect on endothelium dependent blood flow but has a significant effect on endothelium independent blood flow and insulin resistance reduction [89]. Conversely, Vitale et al. found significant improvement of endothelium dependent flow without a significant effect on endothelium independent response [90]. Further studies are necessary to establish the effect of metformin on endothelial function.

\section{Effects on body weight}

Metformin may have a neutral effect on body weight of patients with T2DM when compared to diet [18] or may limit or decrease the weight gain experienced with sulfonylureas [18], TDZ [104], insulin [29,75], HAART [97], and antipsychotics drugs [94].

Modest weight loss with metformin has been observed in subjects with IGT $[15,18]$. However, a meta-analysis of overweight and obese non-diabetic subjects, found no significant weight loss as either a primary or as secondary outcome [105].
The mechanisms by which metformin contributes to weight loss may be explained through the reduction in gastrointestinal absorption of carbohydrates and insulin resistance [95], reduction of leptin [95] and ghrelin levels after glucose overload [96], and by induction of a lipolitic and anoretic effect by acting on glucagon-like peptide 1 [40].

\section{Effects on lipid profile}

Metformin is associated with improvements in lipoprotein metabolism, including decreases in LDL-C [95], fasting and postprandial TGs, and free fatty acids [106].

\section{Effects on blood pressure}

The hypertension associated with diabetes has an unclear pathogenesis that may involve insulin resistance. Insulin resistance is related to hypertension in both diabetic and non-diabetic individuals and may contribute to hypertension by increasing sympathetic activity, peripheral vascular resistance, renal sodium retention [107], and vascular smooth muscle tone and proliferation [108,109].

Data of the effects of metformin on BP are variable, with neutral effects or small decreases in SBP and DBP [110]. In the BIGPRO1 trial carried out in upper-body obese non-diabetic subjects with no cardiovascular diseases or contraindications to metformin, blood pressure decreased significantly more in the IFG/IGT subgroup treated with metformin compared to the placebo group $(\mathrm{p}<0.03)[111]$.

\section{Effects on thyroid function}

Metformin decreases serum levels of thyrotropin (TSH) to subnormal levels in hypothyroid patients that use levothyroxin (LT4) on a regular basis [112]. A significant decrease in TSH $(\mathrm{P}<0.001)$ without reciprocal changes in any thyroid function parameter in diabetic patients had also been reported but only in hypothyroid subjects, not in euthyroid ones [113].

The mechanism of the drop in TSH is unclear at this time. Some of the proposed explanations for this effect are enhanced inhibitory modulation of thyroid hormones on central TSH secretion, improved thyroid reserve in patients with hypothyroidism [113], changes in the affinity or the number of thyroid hormone receptors, increased dopaminergic tone, or induced constituent activation of the TSH receptor [112].

\section{Metformin and HIV lypodystrofy}

Antiretroviral therapy has been associated with an increased prevalence of type 2 diabetes mellitus and insulin resistance among HIV-infected patients [114]. Lipodystrophy, characterized by morphological (peripheral lipoatrophy, localized fat accumulation) and metabolic changes (hyperlipidemia, insulin resistance and 
hyperglycemia), is highly prevalent in patients on highly active antiretroviral therapy (HAART), occurring in 40\% to $80 \%$ of patients [115].

Nucleoside reverse transcriptase inhibitors (NRTIs), particularly thymidine analogues (zidovudine and stavudine), have been associated with morphological changes, particularly extremity fat loss [116], while protease inhibitors (PIs) have been associated with biochemical derangements of glucose and lipids as well as with localized accumulation of fat [117].

Lifestyle modifications such as diet and exercise and switching antiretroviral therapies seems to be of limited value in reducing visceral abdominal fat (VAT). Metformin has been shown to reduce VAT $[97,98]$ but at the expense of accelerating peripheral fat loss [118]. Favorable effects on insulin levels [98], insulin sensitivity [119], weight [97], flow-mediated vasodilation [119], and lipid profiles [98,119] have also been described.

\section{Effects on hemostasis}

Therapeutic doses of metformin in type 2 diabetic patients lower circulating levels of several coagulation factors such as plasminogen activator inhibitor (PAI-1), von Williebrand Factor (vWF), tissue type plasminogen activator [88], factor VII [91]. It has also direct effects on fibrin structure and function by decreasing factor XIII activity and changing fibrin structure [92].

Furthermore, plasma levels of PAI-1 and vWF, which are secreted mainly by the impaired endothelium, have been shown to decrease with metformin therapy in nondiabetic subjects [93].

\section{Metformin and neuroprotection}

Alzheimer's disease (AD), one of the most common neurodegenerative diseases, has been termed type 3 diabetes. It is a brain specific form of diabetes characterized by impaired insulin actions and neuronal insulin resistance [120] that leads to excessive generation and accumulation of amyloid oligomers, a key factor in the development of AD [121].

The mechanisms of cerebral metabolism are still unclear. A network of different factors is most likely responsible for its maintenance. The activated protein kinase (AMPK) forms a molecular hub for cellular metabolic control [122]. Recent studies of neuronal models are pointing to possible AMPK roles beyond energy sensing with some reporting protective effects [123] while others report detrimental effects, particularly under extreme energy depletion [124].

AMPK is activated in the brain by metabolic stresses that inhibit ATP production such as ischemia, hypoxia, glucose deprivation, metabolic inhibitors (metformin), as well as catabolic and ATP consuming processes [122].
The human brain is characterized by an elevated oxidative metabolism and low antioxidants enzymes, which increases the brain's vulnerability to oxidative stress [125]. Oxidative stress has been implicated in a variety of neurological diseases, including Alzheimer's disease, Parkinson's disease, and amyotrophic lateral sclerosis disease [126]. Mitochondrial dysfunction has a pivotal role in oxidative stress. In this setting, the permeability transition pore (PTP) acts as a regulator of the apoptotic cascade under stress conditions, triggering the release of apoptotic proteins and subsequent cell death [127]. It was reported that metformin prevents PTP opening and subsequent cell death in various endothelial cell types exposed to high glucose levels [128]. Metformin could interrupt the apoptotic cascade in a model of ectoposide-induced cell death by inhibiting PTP opening and blocking the release of cytochrome-c. These events together with other factors from the mitochondrial intermembrane space are critical processes in the apoptotic cascade [125].

Insulin has been shown to regulate a wide range of processes in the central nervous system such as food intake, energy homeostasis, reproduction, sympathetic activity, learning and memory [129], as well as neuronal proliferation, apoptosis, and synaptic transmission [130].

With regard to $\beta$ amyloid, a report has shown that metformin increases $B$ amyloid in cells through an AMPK-dependent mechanism, independent of insulin signaling and glucose metabolism. This effect is mediated by a transcriptional upregulation of $B$ secretase (BACE 1) which leads to an increase of $B$ amyloid [131]. However, when insulin is added to metformin, it potentiates insulin's effects on amyloid reduction, improves neuronal insulin resistance, and impairs glucose uptake and $\mathrm{AD}$-associated neuropathological characteristics by activating the insulin signaling pathway [129].

Metformin has been shown to promote rodent and human neurogenesis in culture by activating a protein kinase C-CREB binding protein (PKC-CBP) pathway, recruiting neural stem cells and enhancing neural function, particularly spatial memory function. It is noteworthy that neural stem cells can be recruited in an attempt of endogeneously repairing the injured or regenerating brain [132]. In the context of metformin's potential neuroprotective effect in vivo, the capacity of the drug to cross the blood brain barrier needs to be further elucidated. Provided that this crossing could occur, metformin may become a therapeutic agent not only in peripheral and diabetes-associated vascular neuropathy but also in neurodegenerative diseases.

\section{Metformin and cancer}

Patients with type 2 diabetes have increased risks of various types of cancer, particularly liver, pancreas, endometrium, colon, rectum, breast, and bladder cancer. Cancer mortality 
is also increased [133,134]. Many studies showed reduced incidence of different types of cancer in patients as well a reduced cancer-related mortality in patients using metformin (Table 3).

The underlying mechanisms of tumorigenesis in T2DM seem to be related to insulin resistance, hyperinsulinemia, elevated levels of IGF-1 [140-142], and hyperglycemia with the latter driving ATP production in cancer cells through the glycolytic pathway, a mechanism known as the Warburg effect [142].

Metformin significantly reduces tumorigenesis and cancer cell growth although how it does it is not well understood. It may be due to its effects on insulin reduction and hyperinsulinemia, and consequently on IGF-1 levels, which have mitogenic actions enhancing cellular proliferation,but may also involve specific AMPKmediated pathways [133].

Activation of AMPK leads to inhibition of mTOR through phosphorylaton and subsequent activation of the tumor suppressor tuberous sclerosis complex 2 (TSC2). The mTOR is a key integrator of growth factor and nutrient signals as well as a critical mediator of the $\mathrm{PI} 3 \mathrm{~K} / \mathrm{PKB} / \mathrm{Akt}$ pathway, one of the most frequently disregulated signaling pathways in human cancer [144]. Metformin may have additional anticancer properties independent of AMPK, liver kinase 1 (LKB1), and TSC2. This may be related, in part, to the inhibition of Rag GTPase-mediated activation of mTOR [145].

Patients with type 2 diabetes who are prescribed metformin had a lower risk of cancer compared to patients who did not take it. The reduced risk of cancer and cancer mortality observed in these studies has been consistently in the range of $25 \%$ to $30 \%$ [135-139,145-147]. An observational cohort study with type 2 diabetics who were new metformin users found a significant decrease in cancer incidence among metformin users (7.3\%) compared to controls (11.6\%). The unadjusted hazard ratio (95\% CI) for cancer was $0.46(0.40-0.53)$. The authors suggested a dose-related response [136]. In an observational study of women with type 2 diabetes, a decreased risk of breast cancer among metformin users was only seen with long-term use [137].

Metformin use is associated with lower cancer-related mortality. A prospective study (median follow-up time of 9.6 years) found that metformin use at baseline was associated with lower cancer-related mortality and that this association appeared to be dose dependent [138]. Diabetic patients with colorectal cancer who were treated with metformin had lower mortality than those not receiving metformin [139]. Patients with type 2 diabetes exposed to sulfonylureas and exogenous insulin had a significantly increased risk of cancer-related mortality compared with patients exposed to metformin. However, whether this increased risk is related to a deleterious effect of sulfonylurea and insulin or a protective effect of metformin or due to some unmeasured effect related to both choice of therapy and cancer risk is not known [147].

The proposed mechanisms of metformin anti-cancer properties are not fully understood. Most are mainly mediated through AMPK activation which requires LKB1, a well-known tumor suppressor [2]. Some of these mechanisms may be through inhibition of cell growth [148], IGF-1 signaling [149], inhibition of the mTOR pathway [150], reduction of human epidermal growth factor receptor type 2 (HER-2) expression (a major driver of proliferation in breast cancer) [151], inhibition of angiogenesis and inflammation [152], induction of apoptosis and protein 53 (p53) activation [153], cell cycle arrest $[137,154]$, and enhancement of cluster of differenciation 8 (CD8) T cell memory [155].

\section{Future roles for metformin in cancer therapy}

In vitro and in vivo studies strongly suggest that metformin may be a valuable adjuvant in cancer treatment. Some of the proposed future roles yet to be defined through further research are outlined as follows:

Table 3 Reduced incidence and cancer-related mortality in metformin treated patients

\begin{tabular}{|c|c|c|c|c|c|c|}
\hline Author & Study type & Tumor type & Region & $\begin{array}{l}\text { Total } \\
\text { participants }\end{array}$ & $\begin{array}{l}\text { Follow } \\
\text { up } \\
\text { (years) }\end{array}$ & Confounding adjustment * \\
\hline $\begin{array}{l}\text { Evans } \\
{[135]}\end{array}$ & $\begin{array}{l}\text { Pilot } \\
\text { Observational } \\
\text { Study }\end{array}$ & Not specified & $\begin{array}{l}\text { Tayside, } \\
\text { Scotland. } \\
\text { UK }\end{array}$ & 11,876 & 8 & IMC, smoking, blood pressure, material deprivation \\
\hline $\begin{array}{l}\text { Bodmer } \\
{[136]}\end{array}$ & $\begin{array}{l}\text { Retrospective } \\
\text { Case control }\end{array}$ & Breast & UK & 22,661 & 10 & $\begin{array}{l}\text { Age, BMl, smoking, estrogen use, diabetes history, } \mathrm{HbA1c} \text {, renal } \\
\text { failure, congestive heart failure, ischemic heart disease }\end{array}$ \\
\hline Li [137] & $\begin{array}{l}\text { Prospective } \\
\text { case-control }\end{array}$ & Pancreatic & USA & 1,836 & 4 & $\begin{array}{l}\text { Sex, age, smoking, DM-2, duration of diabetes, } \mathrm{HbA} 1 \mathrm{c} \text {, insulin } \\
\text { use, oral antidiabetic medication, IMC, risk factors }\end{array}$ \\
\hline $\begin{array}{l}\text { Donadon } \\
{[138]}\end{array}$ & $\begin{array}{l}\text { Retrospective } \\
\text { Case-control }\end{array}$ & $\begin{array}{l}\text { Hepatocellular } \\
\text { carcinoma }\end{array}$ & Italy & 1,573 & 12 & $\begin{array}{l}\text { Sex, age, BMI, alcohol abuse, HBV and HCV infection, DM-2, ALT } \\
\text { level }\end{array}$ \\
\hline \multirow{2}{*}{$\begin{array}{l}\text { Libby } \\
\text { [139] }\end{array}$} & \multirow{2}{*}{$\begin{array}{l}\text { Retrospective } \\
\text { cohort study }\end{array}$} & \multirow[t]{2}{*}{ Colorectal } & \multirow{2}{*}{$\begin{array}{l}\text { Scotland. } \\
\text { UK }\end{array}$} & \multirow[t]{2}{*}{8,000} & \multirow[t]{2}{*}{9} & Sex, age, BMI, HbA1c, deprivation \\
\hline & & & & & & Other drug use \\
\hline
\end{tabular}

*Confounding adjustment: Adjustment of variables that could potentially interfere with cancer incidence. 


\section{Tumor prevention}

When compared to those on other treatments, metformin users had a lower risk of cancer. A doserelationship has been reported $[138,144,145]$.

\section{Adjunct in chemotherapy}

Type 2 diabetic patients receiving neo-adjuvant chemotherapy for breast cancer as well as metformin were more likely to have pathologic complete response $(\mathrm{pCR})$ than patients not receiving it. However, despite the increase in $\mathrm{pCR}$, metformin did not significantly improve the estimated 3-year relapse-free survival rate [156].

\section{Tumor relapse prevention}

Cancer stem cells may be resistant to chemotherapeutic drugs, therefore regenerating the various tumor cell types and promoting disease relapse. Low doses of metformin inhibited cellular transformation and selectively killed cancer stem cells in four genetically different types of breast cancer in a mouse xenograft model. The association of metformin and doxorubicin killed both cancer stem cells and nonstem cancer cells in culture. This may reduce tumor mass and prevent relapse more effectively than either drug used as monotherapy [157].

\section{Metformin contraindications}

Metformin is contraindicated in patients with diabetic ketoacidosis or diabetic precoma, renal failure or renal dysfunction, and acute conditions which have the potential for altering renal function such as: dehydration, severe infection, shock or intravascular administration of iodinated contrast agents, acute or chronic disease which may cause tissue hypoxia (cardiac or respiratory failure, recent myocardial infarction or shock), hepatic insufficiency, and acute alcohol intoxication in the case of alcoholism and in lactating women [158]. Several reports in literature related an increased risk of lactic acidosis with biguanides, mostly phenformin, with an event rate of 40-64 per 100,000 patients years [159] whereas the reported incidence with metformin is 6.3 per 100,000 patients years [160].

Structural and pharmacokinetic differences in metformin such as poor adherence to the mitochondrial membrane, lack of interference with lactate turnover, unchanged excretion, and inhibition of electron transport and glucose oxidation may account for such differences [161].

Despite the use of metformin in cases where it is contraindicated, the incidence of lactic acidosis has not increased. Most patients with case reports relating metformin to lactic acidosis had at least one or more predisposing conditions for lactic acidosis [161].

Renal dysfunction is the most common risk factor associated with lactic acidosis but so far there is no clear evidence indicating at which level of renal dysfunction metformin should be discontinued or contraindicated in order to prevent lactic acidosis. Some authors have suggested discontinuing its use when serum creatinine is above $1.5 \mathrm{mg} / \mathrm{dL}$ in men and $1.4 \mathrm{mg} / \mathrm{dL}$ in women [103] while others suggested a cut-off of $2.2 \mathrm{mg} / \mathrm{dL}$ and continuous use even in the case of ischaemic cardiopathy, chronic obstructive pulmonary disease, or cardiac failure [84].

As serum creatinine can underestimate renal dysfunction, particularly in elderly patients and women, the use of estimated GFR (eGFR) has been advocated. The recommended eGFR thresholds are generally consistent with the National Institute for Health and Clinical Excellence guidelines in the U.K. and those endorsed by the Canadian Diabetes Association and the Australian Diabetes Society. Metformin may be continued or initiated with an eGFR of $60 \mathrm{~mL} / \mathrm{min}$ per $1.73 \mathrm{~m}^{2}$ but renal function should be monitored closely (every 3-6 months). The dose of metformin should be reviewed and reduced (e.g. by $50 \%$ or to half-maximal dose) in those with an eGFR of $45 \mathrm{~mL} / \mathrm{min}$ per $1.73 \mathrm{~m}^{2}$, and renal function should be monitored closely (every 3 months). Metformin should not be initiated in patients at this eGFR [162]. The drug should be stopped once eGFR falls to $30 \mathrm{~mL} / \mathrm{min}$ per $1.73 \mathrm{~m}^{2}$. Frid et al. supports these recommendations through findings that above $30 \mathrm{ml} / \mathrm{min} / 1.73 \mathrm{~m}^{2}$ metformin levels rarely goes above $20 \mathrm{mmol} / \mathrm{l}$, which seems to be a safe level [163].

Another clinical condition associated with lactic acidosis in patients using metformin is heart failure [79].

\section{Adverse effects}

Gastrointestinal intolerance occurs quite frequently in the form of abdominal pain, flatulence, and diarrhea [164]. Most of these effects are transient and subside once the dose is reduced or when administered with meals. However, as much as $5 \%$ of patients do not tolerate even the lowest dose [165].

About $10-30 \%$ of patients who are prescribed metformin have evidence of reduced vitamin B12 absorption due to calcium-dependent ileal membrane antagonism, an effect that can be reversed with supplemental calcium [166]. This vitamin B12 deficiency is rarely associated with megaloblastic anemia [167].

A multicentric study reported a mean decrease of $19 \%$ and $5 \%$ in vitamin $\mathrm{B} 12$ and folate concentration, respectively [168]. Vitamin B12 deficiency has been related with dose and duration of metformin use and occurs more frequently among patients that use it for more than 3 years and in higher doses [169].

Other adverse reactions are sporadic, such as leucocytoclastic vasculitis, allergic pneumonitis [170], cholestatic jaundice [171], and hemolytic anaemia [172].

Hypoglycemia is very uncommon with metformin monotherapy [173] but has been reported in combination 
regimens [174], likely due to metformin potentiating other therapeutic agents.

\section{Drug interactions}

Clinically significant drug interactions involving metformin are rare. Some cationic agents such as amiloride, digoxin, morphine, procainamide, quinidine, quinine, ranitidine, triamterene, trimethoprim, and vancomycin that are eliminated by renal tubular secretion may compete with metformin for elimination. Concomitant administration of cimetidine, furosemide, or nifedipine may also increase the concentration of metformin. Patients receiving metformin in association with these agents should be monitored for potential toxicity. Metformin should be discontinued at least 48 hours prior to the administration of iodinated contrast media which can produce acute renal failure and should only be restarted if renal function is normal [175].

\section{Tolerability}

Gastrointestinal side-effects are common with the use of metformin of standard release and are usually associated with rapid titration and high-dose initiation of metformin.

These effects are generally transient, arise early in the course of treatment, and tend to subside over time [176]. The gastrointestinal side-effects can be addressed by taking the agent with meals, reducing the rate of dose escalation, or transferring to a prolonged-release formulation [177].

Some studies point to a dose-related relationship of the incidence of side-effects [178] whereas other evidence gives no support for a dose-related effect of metformin on the gastrointestinal system [179].

\section{Metformin XR}

The metformin XR formulation releases the active drug through hydrated polymers which expand after uptake of fluid, prolonging gastric residence time which leads to slower drug absorption in the upper gastrointestinal tract and allows once-daily administration [180].

A prospective open label study assessed metformin XR effectiveness on three cardiovascular risk factors: blood glucose (HbA1c, fasting blood glucose, and postprandial blood glucose); total cholesterol, LDL cholesterol, HDL cholesterol; and triglycerides and blood pressure. No significant differences were observed by any anthropometric, clinical, or laboratory measures except for plasma triglycerides which were lower in the group switched to metformin XR [181]. Metformin tolerability as well as patient acceptance was greater in the group switched to metformin XR. Other studies have found good to excellent glycemic control with metformin XR in type 2 diabetic patients who did not have well-controlled diet and exercise alone [182]. Metformin XR has been associated with improved tolerability [182] and increased compliance [183].

\section{Conclusions}

In recent years, metformin has become the first-line therapy for patients with type 2 diabetes. Thus far, metformin is the only antidiabetic agent which has shown reduced macrovascular outcomes which is likely explained by its effects beyond glycemic control. It has also been employed as an adjunct to lifestyle modifications in pre-diabetes and insulin-resistant states. A large amount of evidence in literature supports its use even in cases where it would be contra-indicated mainly due to the fear of lactic acidosis which has been over-emphasized as the available data suggest that lactate levels and risk of lactic acidosis do not differ appreciably in patients taking this drug versus other glucose-lowering agents. It has also recently gained attention as a potential treatment for neurodegenerative diseases such as Alzheimer's disease.

\begin{abstract}
Abbreviations
ACE: Angiotensin converting enzyme; AD: Alzheimeir disease; AGE: Advanced glycosilation end product; AMPK: Adenosine monophosfatase protein kinase; BACE 1: Beta-amyloid cleaving enzyme- 1; BMI: Body muscular index; BP: Blood pressure; CAD: Coronary artery disease; CDK: Cyclin dependent kinase; CHF: Cardiac heart failure; CPR: Complete pathologic response; CREB: CAMP responsive element binding protein; CsA: Cyclosporin A; CVD: Cardiovascular disease; DDPPIV: Dipeptidyl peptidase IV; DM: Diabetes mellitus; DYm: Mitochondrial membrane potential; FPG: Fasting plasma glucose; GDM: Gestacional diabetes mellitus; GFR: Glomerular filtration rate; eGFR: Estimated glomerular filtration rate; GLP-1: Glucagon like peptide 1; HAART: Highly active antiretroviral therapy; HALS: HIV associated lipodystrophy syndrome; HIV: Human imunodeficiency virus; HER-2: Human epidermal growth factor receptor type 2; HF: Heart failure; HOMA-

IR: Homeostatic model assessment - insulin resistance; IFG: Impaired fasting glucose; IGT: Impaired glucose tolerance; LKB-1: Liver kinase 1; LSM: Lifestyle modification; MET: Metformin; MG: Metylglyoxal; mTOR: Mammalian target of rapamycin; NF-KB: Nuclear factor kappa beta; NRTIs: Nucleoside reverse transcriptase inhibitors; OGT: Oral glucose tolerance test; PAI-1: Plasminogen activator inhibitor; PCOS: Policystic ovary syndrome; PIs: Protease inhibitors; PTP: Permeability transition pore; ROS: Reactive oxigen species; SIRT-1: Sirtuin 1; T2DM: Type 2 diabetes mellitus; TCS2: Tuberous sclerosis complex 2; TORC2: Transducer of regulated CREB protein 2; TZP: Triazepinone; UCPs: Uncoupled proteins; VEGF: Vascular endothelial growth factor; Vwf: Von Williebrand fator.
\end{abstract}

\section{Competing interests}

The authors declare that they have no competing interests.

\section{Authors' contributions}

Lilian Beatiz Aguayo Rojas drafted the manuscript and Marilia Brito Gomes reviewed and edited the manuscript. Both authors read and approved the final manuscript.

\section{Authors' information}

Lilian Beatriz Aguayo Rojas is post graduate student at the State University of Rio de Janeiro, Diabetes Unit, Internal Medicine Department.

Marilia Brito Gomes is an Associate Professor at the State University of Rio de Janeiro, Diabetes Unit, Internal Medicine Department.

Received: 12 December 2012 Accepted: 5 February 2013

Published: 15 February 2013

\section{References}

1. Godarzi MO, Brier-Ash M: Metformin revisited: re-evaluation of its properties and role in the pharmacopoeia of modern antidiabetic agents. Diabetes Obes Metab 2005, 5:654-665. 
2. Shaw RJ, Lamia KA, Vasquez D, et al: The kinase LKB1 mediates glucose homeostasis in liver and therapeutic effects of metformin. Science 2005, 310:1642-1646.

3. El-Mir MY, Nogueira V, Fontaine E, et al: Dimethylbiguanide inhibits cell respiration via an indirect effect targeted on the respiratory chain complex I. J Biol Chem 2000, 275:223-228.

4. Wild S, Roglic G, Green A, Sicree R, King H: Global prevalence of diabetes. Estimates for the year 2000 and projections for 2030. Diabetes Care 2004 27:1047-1053

5. Guillies C, Abram KR, Lambert PC, Cooper NJ, Sutton AJ, et al: Pharmacological and lifestyle interventions to prevent or delay type 2 diabetes in people with impaired glucose tolerance: systematic review and meta-analysis. BMJ 2007, 334:299.

6. Petersen J, MC Guire D: Impaired glucose tolerance and impaired fasting glucose - a review of diagnosis, clinical implications and management. Diabetes Vasc Dis Res 2005, 2(1):9-15.

7. Diabetes Prevention Program Research Group: Reduction in the incidence of type 2 diabetes with lifestyle intervention or metformin. $N$ Engl J Med 2002, 346:393-403.

8. Diabetes Prevention Program Research Group: Effects of withdrawal from metformin on the development of diabetes in the diabetes prevention program. Diabetes Care 2003, 26(4):977-980

9. Ramachandran A, Snehalatha C, Mukesh M, et al: Indian diabetes prevention programme (IDPP). the Indian diabetes prevention programme shows that lifestyle modification and metformin prevent type 2 diabetes in Asian Indian subjects with impaired glucose tolerance (IDPP-1). Diabetologia 2006, 49:289-297.

10. Yang $W$, Lin L, Qi J, et al: The preventive effect of acarbose and metformin on the IGT population from becoming diabetes mellitus: a 3year multicentral prospective study. Chin J Endocrinol Metab 2001, 17:131-134.

11. Diabetes Prevention Program Research Group: 10-year follow-up of diabetes incidence and weight loss in the Diabetes Prevention Program Outcomes Study. Lancet 2009, 374(9702):1677-1686.

12. Ramachandran $A$, Snehalatha C, Vijay V: Low risk threshold for acquired diabetogenic factors in Asian Indians. Diab Res Clin Pract 2004, 65:189-195.

13. Pan XR, Li GW, Hu YH, et al: Effects of diet and exercise in preventing NIDDM in people with impaired glucose tolerance: The Da Qing IGT and Diabetes Study. Diabetes Care 1997, 20:537-544.

14. Salpeter SR, Buckley NS, Kahn JA, et al: Meta-analysis: metformin treatment in persons at risk for diabetes mellitus. Am J Med 2008, 121:149-157.

15. Lily M, Godwin M: Treating prediabetes with metformin systematic review and meta-analysis. Can Fam Physician 2009, 55:363-369.

16. American Diabetes Association: Summary of revisions to the 2011 clinical practice recommendations. Diabetes Care 2011, 34(Suppl 1):S3.

17. Rodbard HW, Jellinger PS, Davidson JA, et al: Statement by an American association of clinical endocrinologists/American college of endocrinology consensus panel on type 2 diabetes mellitus. An algorithm for glycemic control. Endocr Pract 2009, 15(6):540-559.

18. Prospective Diabetes Study (UKPDS) Group: Effect of intensive blood glucose control with metformin on complications in overweight patients with type 2 diabetes (UKPDS 34). Lancet 1998, 352(9131):854-865.

19. Ito $H$, Ishida $H$, Takeuchi $Y$, et al: Long-term effect of metformin on blood glucose control in non-obese patients with type 2 diabetes mellitus. Nutr Metab 2010, 7:83.

20. Turner RC, Cull CA, Frighi V, Holman RR: Glycemic control with diet, sulfonylurea, metformin, or insulin in patients with type 2 diabetes: progressive requirement for multiple therapies (UKPDS 49). JAMA 1999, 281:2005-2012.

21. Gerich J, Raskin P, Jean-Louis $L$, et al: PRESERVE-beta: two-year efficacy and safety of initial combination therapy with nateglinide or glyburide plus metformin. Diabetes Care 2005, 28:2093-2099.

22. Phung OJ, Scholle JM, Talwar M, Coleman Cl: Effect of noninsulin Antidiabetic drugs added to metformin therapy on glycemic control, weight gain, and hypoglycemia in type 2 diabetes. JAMA 2010, 303(14):1410-1418.

23. Charbonnel B, Shernthaner G, Brunetti $P$, et al: Long-term efficacy and tolerability of add-on piogçitazone therapy to faliling monotherapy compared with addition of glicazide or metformin in patients with type 2 diabetes. Diabetologia 2005, 48:1093-1104.
24. Hanefeld M, Brunetti P, Schhernthaner GH, et al: One year glycemic control with sulphonylurea plus pioglitazone versus sulphonylurea plus metformin in patients with type 2 diabetes. Diabetes Care 2004, 27:141-147.

25. González-Ortiza M, Guerrero-Romero J, Violante-Ortiz R, et al: Efficacy of glimepiride/metformin combination versus glibenclamide/metformin in patients with uncontrolled type 2 diabetes mellitus. J Diabetes Complications 2009, 23:376-379.

26. Johnson JA, Majumdar SR, Simpson SH, et al: Decreased mortality associated with the use of metformin compared with sulfonylurea Monotherapy in type 2 diabetes. Diabetes Care 2002, 25:2244-2248.

27. Evans JM, Ogston SA, Emslie-Smith A, Morris AD: Risk of mortality and adverse cardiovascular outcomes in type 2 diabetes: a comparison of patients treated with sulfonylureas and metformin. Diabetologia 2006, 49:930-936.

28. Giugliano D, Quatraro A, Consoli G, et al: Metformin for obese, insulintreated diabetic patients: improvement in glycaemic control and reduction of metabolic risk factors. Eur J Clin Pharmacol 1993, 44:107-112.

29. Lund SS, Tarnow L, Frandsen M, et al: Combining insulin with metformin or an insulin secretagogue in non-obese patients with type 2 diabetes: 12 month, randomised, double blind trial. BJ 2009, 339:b4324.

30. Vella $S$, Buetow $L$, Royle $P$, et al: The use of metformin in type 1 diabetes: a systematic review of efficacy. Diabetologia 2010, 53(5):809-820.

31. Abdelghaffar $\mathrm{S}$, Attia AM: Metformin added to insulin therapy for type 1 diabetes mellitus in adolescents. Cochrane Database Syst Rev 2009, (Issue 1):CD006691.

32. Bailey CJ, Bagdonas A, Rubes J, et al: Rosiglitazone-metformin fixed-dose combination compared with uptritrated metformin alone in type diabetes mellitus:a 24 week, multicenter, randomized, double-blind, parallel-group study. Clin Ther 2005, 27:1548-1561.

33. Retnakaran R, Qi Y, Harris SB, Hanley AJ, Zinman B: Changes over time in glycemic control, insulin sensitivity, and beta-cell function in response to low-dose metformin and thiazolidinedione combination therapy in patients with impaired glucose tolerance. Diabetes Care 2011, 34(7):1601-1604.

34. Scheen AJ: ADOPT study: which first-line glucose-lowering oral medication in type 2 diabetes? Rev Med Liege 2007, 62(1):48-52.

35. Komoroski B, Vachharajani N, Feng Y, Li L, Kornhauser D, Pfister M: Dapagliflozin, a novel, selective SGLT2 inhibitor, improved glycemic control over 2 weeks in patients with type 2 diabetes mellitus. Clin Pharmacol Ther 2009, 85:513-519.

36. List JF, Woo V, Morales E, Tang W, Fiedorek FT: Sodium-glucose cotransport inhibition with dapagliflozin in type 2 diabetes. Diabetes Care 2009, 32:650-657.

37. Scheen AJ, de Magalhanes AC, Salvatore T, et al: Reduction of the acute bioavailability of metformin by the a glycosidase inhibitor acarbose in normal man. Eur J Clin Invest 1994, 24(Suppl3):50-54.

38. Rosenstok J, Brown A, Fischer J, et al: Efficacy and safety of acarbose in metformin-treated patients with type 2 diabetes. Diabetes Care 1998, 21:2050-2055.

39. Richter B, Bandeira-Echtler E, Bergerhoff K, Lerch CL: Dipeptidyl peptidase-4 (DPP-4) inhibitors for type 2 diabetes mellitus. Cochrane Database Syst Rev 2008, (2):CD006739.

40. Mannucci $E$, Ognibene A, Cremasco F, et al: Effect of metformin on glucagon-like peptide 1 (GLP-1) and leptin levels in obese nondiabetic subjects. Diabetes Care 2001, 24:489-494.

41. DeFronzo RA, Hissa MN, Garber AJ, for Saxagliptin Study Group, et al: The efficacy and safety of saxagliptin when added to metformin therapy in patients with inadequately controlled type 2 diabetes with metformin alone. Diabetes Care 2009, 32(9):1649-1655.

42. Deacon CF, Mannucci E, Ahrén B: Glycaemic efficacy of glucagon-like peptide- 1 receptor agonists and dipeptidyl peptidase- 4 inhibitors as add-on therapy to metformin in subjects with type 2 diabetes-a review and meta analysis. Diabetes Obes Metab 2012, 14(8):762-767.

43. Charles B, Norris R, Xiao X, Hague W: Population pharmacokinetics of metformin in late pregnancy. Ther Drug Monit 2006, 28:67-72.

44. Gutzin SJ, Kozer E, Magee LA, Feig DS, Koren G: The safety of oral hypoglycemic agents in the first trimester of pregnancy. a meta-analysis. Can J Clin Pharmacol 2003, 10:179-183.

45. Gilbert C, Valois M, Koren G: Pregnancy outcome after first-trimester exposure to metformin: a meta-analysis. Fertil Steril 2006, 86:658-663. 
46. Rowan JA, Hague WM, Gao W, Battin MR, Moore MP: MiG trial investigators. Metformin versus insulin for the treatment of gestational diabetes. N Engl J Med 2008, 358:2003-2015.

47. Moore LE, Briery CM, Clokey D, et al: Metformin and insulin in the management of gestational diabetes mellitus: preliminary results of a comparison. J Reprod Med 2007, 52:1011-1015.

48. Rowan JA, Rush EC, Obolonkin V, Battin M, Wouldes T, Hague WM: Metformin in gestational diabetes: the offspring follow-up (MiG TOFU): body composition at 2 years of age. Diabetes Care 2011, 34:2279-2284.

49. Wiegand S, Maikowski U, Blankenstein O, Bierbermann H, Tarnow P, Grutes A: Type 2 diabetes and impaired glucose tolerance in European children and adolescents with obesity- a problem that is no longer restrited to minority groups. Eur J Endocrinol 2004, 151:199-206.

50. Pinhas-Hamiel O, Zeitler P: Clinical presentation and treatment of type 2 diabetes in children. Pediatr Diabetes 2007, 8(Suppl. 9):16-27.

51. Jones KL, Arslanian S, Peterokova VA, Park JS, Tomlinson MJ: Effect of metformin in pediatric patients with type 2 diabetes: a randomized controlled trial. Diabetes Care 2002, 25:89-94.

52. Gottschalk M, Danne T, Vlajnic A, Cara J: Glimepiride Versus Metformin as Monotherapy in Pediatric Patients With Type 2 Diabetes.A randomized, single-blind comparative study. DiabetesCare 2007, 30:790-794.

53. Gungor N, Thompson T, Sutton-Tyrrell K, Janosky J, Arslanian S: Early signs of cardiovascular disease in youth with obesityand type 2 diabetes. Diabetes Care 2005, 28(5):1219-1221.

54. Freedman DS, Khan LK, Dietz WH, Srinivasan SR, Berenson GS: Relationship of childhood obesity to coronary heart disease risk factors in adulthood: the Bogalusa Heart Study. Pediatrics 2001, 108(3):712-718.

55. Rashid M, Roberts EA: Nonalcoholic steatohepatitis in children. J Pediatr Gastroenterol Nutr 2000, 30:48-53.

56. Targher G, Bertolini L, Poli F, et al: Nonalcoholic fatty liver disease and risk of future cardiovascular events among type 2 diabetic patients. Diabetes 2005, 54:3541-3546.

57. Carnethon MR, Gidding SS, Nehgme R, Sidney S, et al: Cardiorespiratory fitness in young adulthood and the development of cardiovascular disease risk factors. JAMA 2003, 290:3092-3100.

58. Schwimmer JB, Deutsch $R$, Kahen $T$, Lavine JE, Stanley C, Behling C: Prevalence of fatty liver in children and adolescents. Pediatrics 2006, 118:1388-1393.

59. Reinehr T, Kiess W, Kappellen T, Andler W: Insulin sensitivity among obese children and adolescents, according to degree of weight loss. Pediatrics 2004, 114:1569-1573

60. Tock L, D^amaso A, de Piano A, Carnier J, et al: Long-TermEffects of metformin and lifestyle modification on nonalcoholic fatty liver disease obese adolescents. J Obes 2010, 831901:6. Article ID 831901.

61. Burgert TS, Duran EJ, Goldberg-Gell R, Dziura J, Yeckel CW, Katz S, Tamborlane W, Caprio S: Short-term metabolic and cardiovascular effects of metformin in markedly obese adolescents with normal glucose tolerance. Pediatr Diabetes 2008, 9:567-576.

62. Park M, Kinra S, Ward K, White B, Viner R: Metformin for obesity in children and adolescents: a systematic review. Diabetes Care 2009, 32:1743-1745.

63. Cole CR, Foody JM, Blackstone EH, Lauer MS: Heart rate recovery after submaximal exercise testing asa predictor of mortality in a cardiovascularly healthy cohort. Ann Intern Med 2000, 132:552-555.

64. Lind $L$, Andren $B$ : Heart rate recovery after exercise is related to the insulin resistance syndrome and heart rate variability in elderly men. Am Heart J 2002, 144:666-672.

65. Nadeau KJ, Ehlers LB, Zeitler PS, Love-Osborne K: Treatment of nonalcoholic fatty liver disease with metformin versus lifestyle intervention in insulin-resistant adolescents. Pediatr Diabetes 2009, 10:5-13.

66. Oude Luttikhuis $H$, Baur L, Jansen H, Shrewsbury VA, O'Malley C, Stolk RP Summerbell CD: Interventions for treating obesity in children. Cochrane Database Syst Rev 2009, (1):CD001872.

67. Kannel WB, McGee DL: Diabetes and glucose tolerance as risk factors for cardiovascular disease: the Framingham Study. Diabetes Care 1979, 2:120-126.

68. Wingard DL, Barrett-Connor E: Heart disease and diabetes, NationalDiabetes Data Group. Diabetes in America. 2nd edition. Washington, D.C: GPO; 1995:429-48. NIH publication no.95-1468.

69. Haffner SM, Lehto S, Ronnemaa T, Pyorala K, Laakso M: Mortality from coronary heart disease in subjects with type 2 diabetes and in nondiabetic subjects with and without prior myocardial infarction. N Engl J Med 1998, 339:229-234.

70. Krempf M, Parhofer KG, Steg G, et al: National Cholesterol Education Program (NCEP) Expert Panel onDetection, Evaluation, and Treatment of High Blood Cholesterol in Adults (Adult Treatment Panel III).Third Report of the NationalCholesterol Education Program (NCEP) Expert Panel on Detection. Circulation 2002, 106:3143-3421.

71. Bulugahapitiya U, Siyambalapitiya S, Sithole J, Idris I: Is diabetes a coronary risk equivalent? Systematic review and meta-analysis. Diabet Med 2009, 26:142-148.

72. Sgambato S, Varricchio M, Tesauro P, Passariello N, Carbone L: Use of metformin in ischemic cardiopathy. Clin Ther 1980, 94:77-85.

73. Holman RR, Paul SK, Bethel MA, Matthews DR, Neil HA: 10-year follow up of intensive glucose control in type 2 diabetes. N Engl J Med 2008, 359:1577-1589.

74. Kao J, Tobis J, Mc Clelland RL, et al: Relation of metformin treatment to clinical events in diabetic patients undergoing percutaneous intervention. Am J Cardiol 2004, 93:1347-1350.

75. Kooy A, de Jager J, Lehert $P$, et al: Long-term effects of metformin on metabolism and microvascular and macrovascular disease in patients with type 2 diabetes mellitus. Arch Intern Med 2009, 169:616-625.

76. Jadhav S, Ferrell W, Greer IA, Petrie JR, Cobbe SM, Sattar N: Effects of metformin on microvascular function and exercise tolerance in women with angina and normal coronary arteries. J Am Coll Cardiol 2006, 48:956-963.

77. Boussageon R, Supper I, Bejan-Angoulvant T, et al: Reappraisal of metformin efficacy in the treatment of type 2 diabetes: a meta-analysis of randomised controlled trials. PLoS Med 2012, 9(4):e1001204.

78. MacDonald MR, Petrie MC, Hawkins NM, et al: Diabetes, left ventricular systolic dysfunction, and chronic heart failure. Eur Heart J 2008, 10:1224-1240

79. Hulisz DT, Bonfiglio MF, Murray RD: Metformin-associated lactic acidosis. J Am Board Fam Pract 1998, 11:233-236.

80. Food and Drug Administration. Product label approval: metformin. 2006 http://packageinserts.bms.com/pi/piglucophage.pdf

81. Masoudi FA, Inzucchi SE, Wang Y, Havranek EP, Foody JM, Krumholz HM Thiazolinediones, metformin, and outcomes in older patients with diabetes and heart failure. Circulation 2005, 111:583-590.

82. Eurich DT, Majumdar SR, McAlister FA, Tsuyuki RT, Johnson JA: Improved clinical outcomes associated with metformin in patients with diabetes and heart failure. Diabetes Care 2005, 28:2345-2351.

83. Papanas N, Maltezos E, Mikhailidis DP: Metformin and heart failure: never say never again. Expert Opin Pharmacother 2012, 1:1-8.

84. Rachmani R, Slavachevski I, Levi Z, Zadok B, Kedar Y, Ravid M: Metformin in patients with type 2 diabetes mellitus: reconsideration of traditional contraindications. Eur J Intern Med 2002, 13:428-433.

85. Shah DD, Fonarow GC, Horwich TB: Metformin Therapy and Outcomes in Patients With Advanced Systolic Heart Failure and Diabetes. J Card Fail 2010, 16(3):200-206.

86. Isoda K, Young J, Zirlik A, et al: Metformin inhibits Proinflammatory Responses and Nuclear Factor $\mathrm{K} ß$ in Human Vascular Wall Cells. Arterioscler Thromb Vasc Biol 2006, 26:611-617.

87. The Diabetes Prevention Program Research Group Intensive: Lifestyle Intervention or Metformin on Inflammation and Coagulation in Participants With Impaired Glucose Tolerance. Diabetes 2005, 54(5):1566-1572.

88. De Jager J, Kooy A, Lehert $P$, et al: Effects of short-term treatment with metformin on markers of endothelial function and inflammatory activity in type 2 diabetes mellitus: a randomized, placebo-controlled trial. J Intern Med 2004, 256:1-14.

89. Mather KJ, Verma S, Anderson TJ: Improved endothelial function with metformin in type 2 diabetes mellitus. J Am Coll Cardiol 2001, 37(5):1344-1350.

90. Vitale C, Mercuro G, Cornoldi A, Fini M, et al: Metformin improves endothelial function in patients with metabolic syndrome. J Intern Med 2005, 258:250-256.

91. Grant PJ: Beneficial effects of metformin on haemostasis and vascular function in man. Diabetes Metab 2003, 29(6S):44-52.

92. Standeven KF, Ariens RA, Whitaker $P$, et al: The effect of dimethylbiguanide on thrombin activity, FXIII activation, fibrin polymerization, and fibrin clot formation. Diabetes 2002, 51:189-197.

93. Charles MA, Morange $P$, Eschwege $E$, et al: Effect of weight change and metformin on fibrinolysis and the von Willebrand factor in obese 
nondiabetic subjects: the BIGPRO1 Study. Biguanides and the Prevention of the Risk of Obesity. Diabetes Care 1998, 21:1967-1972

94. Wu RR, Zhao JP, Jin H, et al: Lifestyle Intervention and Metformin for Treatment of Antipsychotic-Induced Weight Gain A Randomized Controlled Trial. JAMA 2008, 299(2):185-193.

95. Glueck CJ, Fontaine RN, Wang P, et al: Metformin reduces weight, centripetalobesity, insulin, leptin, and low-density lipoprotein cholesterol in nondiabetic, morbidly obese subjects with body mass index greater than 30. Metabolism 2001, 50:856-861.

96. Kusaka I, Nagasaka S, Horie H, Ishibashi S: Metformin, but not pioglitazone decreases postchallenge plasma ghrelin levels in type 2 diabetic patients: a possible role in weight stability? Diabetes Obes Metab 2008, 10:1039-1046.

97. Hadigan C, Corcoran C, Basgoz N, et al: Metformin in the Treatment of HIV Lipodystrophy Syndrome A Randomized Controlled Trial. JAMA 2000, 284:472-477.

98. Sheth S, Larson L: The efficacy and safety of insulin-sensitizing drugs in HIV-associated lipodystrophy syndrome: a meta-analysis of randomized trials. BMC Infect Dis 2010, 10:183

99. Bailey CJ, Turner RC: Metformin. N Engl J Med 1996, 334:574-579.

100. Faure $P$, Rossini $E$, Wiernsperger $N$, et al: An insulin sensitizer improves the free radical defense system potential and insulin sensitivity in high fructose-fed rats. Diabetes 1999, 48:353-357.

101. Beisswenger $P$, Rugiero-Lopez D: Metformin inhibition of glycation processes. Diabetes Metab 2003, 29(6S):95-103.

102. Anedda A, Rial E, Gonzalez Barroso: Metformin induces oxidative stress in white adipocytes and raises uncoupling proten levels. J Endocrinol 2008, 199:33-40.

103. Zheng Z, Chen H, Li J, Li T, Zheng B, Zheng Y, Jin H, He Y, Gu Q, Xun X: Sirtuin 1-mediated cellular metabolic memory of high glucose via the LKB1/AMPK/ROS pathway and therapeutic effects of metformin. Diabetes 2012, 61(1):217-228.

104. Kahn SE, Haffner SM, Heise MA, et al: Glycemic durability of rosiglitazone, metformin or glyburide monotherapy. N Engl J Med 2006, 355:2427-2443.

105. Desilets AR, Dhakal-Karki S, Dunican KC: Role of metformin for weight management in patients without type 2 diabetes. Ann Pharmacother 2008, 42:817-826.

106. Eleftheriadou I, Grigoropoulou P, Katsilambros N, Tentolouris N: The effects of medications used for the management of diabetes and obesity on postprandial lipid metabolism. Curr Diabetes Rev 2008, 4:340-356.

107. Wulffelé MG, Kooy A, Lehert P, Bets D, Donker A, Stehouwer C: Does metformin decrease blood pressure in patients with type 2 diabetes intensively treated with insulin? Diabet Med 2005, 22:907.

108. Tack CJ, Smits P, Willemsen JJ, Lenders JW, Thien T, Lutterman JA: Effects of insulin on vascular tone and sympathetic nervous system in NIDDM. Diabetes 1996, 45:15-22.

109. Sechi LA, Bartoli E: Molecular mechanisms of insulin resistance in arterial hypertension. Blood Press Supp/ 1996, 1:47-54

110. Granberry MC, Fonseca VA: Cardiovascular risk factors associated with insulin resistance: effects of oral antidiabetic agents. Am J CardiovasC Drugs 2005, 5:201-209.

111. Fontbonne A, Diouf I, Baccara-Dinet M, Eschwege E, Charles A: Effects of 1-year treatment with metformin on metabolic and cardiovascular risk factors in non-diabetic upper-body obese subjects with mild glucose anomalies: a post-hoc analysis of the BIGPRO1 trial. Diabetes Metab 2009, 35:385-391.

112. Vigersky R, Filmore-Nassar A, Allan R: Thyrotropin Suppression by Metformin. J Clin Endocrinol Metab 2006, 91:225-227.

113. Capelli C, Rotondi M, Pirola I, Agosti B, Gandossi E, et al: TSH-lowering effect of metformin in type 2 diabetic patients differences between euthyroid, untreated hypothyroid, and euthyroid on L-T4 therapy patients. Diabetes Care 2009, 32:1589-1590.

114. Triant VA, Lee H, Hadigan C, Grinspoon SK: Increased acute myocardial infarction rates and cardiovascular risk factors among patients with HIV disease. J Clin Endocrinol Metab 2007, 92:2506-2512.

115. Kinlaw WB, Marsh B: Adiponectin and HIV-lipodystrophy:taking HAART. Endocrinology 2004, 145:484-486.

116. Moyle GJ, Sabin CA, Cartledge J, et al: A randomized comparative trial of tenofovir DF or abacavir as replacement for a thymidine analogue in persons with lipoatrophy. Acquir Immune Defic Syndr 2006, 20:2043-2050.

117. Behrens G, Dejam A, Schmidt H, et al: Impaired glucose tolerance, b cell function and lipid metabolism in HIV patients under treatment with protease inhibitors. Acquir Immune Defic Syndr 1999, 13:F63-F70.
118. Kohli R, Shevitz A, Gorbach S, Wanke C: A randomized placebo-controlled trial of metformin for the treatment of HIV lipodystrophy. HIV Med 2007 8:420-426

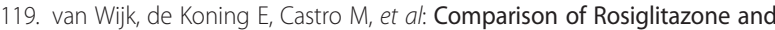
Metformin for treating HIV Lipodistrophy. Ann Inter Med 2005, 143:337-346.

120. Spasic MR, Callaerts P, Norga KK: AMP-Activated Protein Kinase (AMPK) Molecular Crossroad for Metabolic Control and Survival of Neurons. Neuroscientist 2009, 15(4):309-316.

121. Culmsee C, Monnig J, Kemp BE, Mattson MP: AMPactivated protein kinase is highly expressed in neurons in the developing rat brain and promotes neuronal survival following glucose deprivation. J Mol Neurosci 2001 $17: 45-58$.

122. Santomauro Júnior AC, Ugolini MR, Santomauro AT, Souto RP: Metformina e AMPK: Um Antigo Fármaco e Uma Nova Enzima no Contexto da Síndrome Metabólica. Arq Bras Endocrinol Metabol 2008, 52(1):120-125.

123. El-Mir MY, Detaille D, Villanueva G, et al: Neuroprotective Role of Antidiabetic Drug Metformin Against Apoptotic Cell Death in Primary Cortical Neurons. J Mol Neurosci 2008, 34(1):77-87.

124. Andersen JK: Oxidative stress in neurodegeneration: Cause or consequence? Nat Med 2004, 10:S18-S25.

125. Kroemer G, Reed JC: Mitochondrial control of cell death. Nat Med 2000, 6:513-519.

126. Detaille D, Guigas B, Chauvin C, et al: Metformin prevents high glucoseinduced endothelial cell death through a mitochondrial permeability transition-dependent process. Diabetes 2005, 54:2179-2187.

127. Plum L, Schubert M, Bruning JC: The role of insulin receptor signaling in the brain. Trends Endocrinol Metab 2005, 16:59-65.

128. van der Heide LP, Ramakers GM, Smidt MP: Insulin signaling in the central nervous system: learning to survive. Prog Neurobiol 2006, 79:205-221.

129. Gupta A, Bisht B, Dey CS: Peripheral insulin-sensitizer drug metformin ameliorates neuronal insulin resistance and Alzheimer's-like change. Neuropharmacology 2011, 60:910-920

130. Selkoe DJ: The cell biology of ßamyloid precursor protein and presenilin in Alzheimer's disease. Trends Cell Biol 1998, 8:447-453.

131. Chen $Y$, Zhoua $K$, Wanga $R$, Liua $Y$, et al: Antidiabetic drug metformin (GlucophageR) increases biogenesis of Alzheimer's amyloid peptides via up-regulating BACE1 transcription. PNAS 2009, 106(10):3907-3912.

132. Wang J, Gallagher D, De Vito L, et al: Metformin activates an atypical PKCCBP pathway to promote neurogenesis and enhance spatial memory formation. Cell Stem Cell 2012, 11:23-35.

133. Papanas N, Maltezos E, Mikhailidis DP: Metformin and cancer: licence to heal? Expert Opin Investig Drugs 2010, 19:913-917.

134. Larsson SC, Orsini N, Wolk A: Diabetes mellitus and risk of colorectal cancer: a meta-analysis. J Natl Canc Ins 2005, 97:1679-1687.

135. Li D, Yeung SJ, Hassan MM, Konopleva M, Abbruzzese JL: Anti-diabetic therapies affect risk of pancreatic cancer. Gastroenterology 2009, 137(2):482-488.

136. Donadon V, Balbi M, Valent F, Avogaro A: Glycated hemoglobin and antidiabetic strategies as risk factors for hepatocellular carcinoma. World J Gastroenterol 2010, 16(24):3025-3032.

137. Libby G, Donnelly LA, Donnan PT, et al: New users of metformin area at low risk of incident cancer: a cohort study among people with type 2 diabetes. Diabetes Care 2009, 32:1620-1625.

138. Landman GW, Kleefstra N, van Hateren KJ, et al: Metformin associated with lower cancer mortality in type 2 diabetes ZODIAC-16. Diabetes Care 2010, 33:322-326

139. Lee $\mathrm{JH}$, Kim Tl, Jeon SM, et al: The effects of metformin on the survival of colorectal cancer patients with diabetes mellitus. Int J Cancer 2011, $12: 1-24$

140. Inoue $M$, Iwasaki $M$, Otami T, et al: Diabetes mellitus and the risk of cancer. Results from a large-scale population-based cohort study. Arch Intern Med 2006, 166:1871-1877.

141. Grimberg A, Cohen P: Role of insulin-like growth factors and their binding proteins in growth control and carcinogenesis. J Cell Physiol 2000, 183:1-9.

142. Smith U, Gale EAU: Cancer and diabetes: are we ready for prime time? Diabetologia 2010, 53:1541-1544

143. Markman B, Atzori F, Perez-Garcia J, Tabernero J, Baselga J: Status of PI3K inhibition and biomarker development in cancer therapeutics. Ann Oncol 2010, 21:683-691. 
144. Kalender A, Selvaraj A, Kim SY, et al: Metformin, independent of AMPK, inhibits mTORC1 in a rag GTPasedependent manner. Cell Metab 2010, 11:390-401.

145. Evans J, Donelly L, Emslie A, et al: Metformin and reduced risk of cancer in diabetic patients. BMJ 2005, 330(7503):1304-1305

146. Bodmer M, Meier C, Krähenbühl S, et al: Long-term metformin Use is associated with decreased risk of breast cancer. Diabetes Care 2010, 33:1304-1308

147. Bowker SL, Majumdar SR, Veugelers P, Johnson JA: Increased cancerrelated mortality for patients with type 2 diabetes who usesulfonylureas or insulin. Diabetes Care 2006, 29:254-258.

148. Ben Sahra I, Laurent K, Loubat A, et al: The antidiabetic drug metformin exerts an antitumoral effect in vitro and in vivo through a decrease of cyclin D1 level. Oncogene 2008, 27:3576-3586.

149. Pollak M: Insulin and insulin-like growth factor signaling in neoplasia. Nat Rev Cancer 2008, 8:915-928.

150. Zakikhani M, Dowling R, Fantus IG, Sonenberg N, Pollak M: Metformin is an AMP kinase-dependent growth inhibitor for breast cancer cells. Cancer Res 2006, 66:10269-10273.

151. Vazquez-Martin A, Oliveras-Ferraros C, Menendez JA: The antidiabetic drug metformin suppresses HER2 (erbB-2) oncoprotein overexpression via inhibition of the mTOR effector p70S6K1 in human breast carcinoma cells. Cell Cycle 2009, 8:88-96.

152. Lund SS, Tarnow L, Stehouwer CD, et al: Impact of metformin versus repaglinide on non-glycaemic cardiovascular risk markers related to inflammation and endothelial dysfunction in non-obese patients with type 2 diabetes. Eur J Endocrinol 2008, 158:631-641.

153. Thoreen CC, Sabatini DM: AMPK and p53 help cells through lean times. Cell Metab 2005, 1:287-288.

154. Zhuang Y, Miskimins W: Cell cycle arrest in Metformin treated breast cancer cells involves activation of AMPK, downregulation of cyclin D1, and requires p27Kip1 or p21Cip1. J Mol Signal 2008, 3:18.

155. Pearce EL, Walsh MC, Cejas PJ, et al: Enhancing CD8 T-cell memory by modulating fatty acid metabolism. Nature 2009, 460:103-107.

156. Jiralerspong S, Palla S, Giordano S, et al: Metformin and Pathologic Complete Responses to Neoadjuvant Chemotherapy in Diabetic Patients With Breast Cancer. J Clin Oncol 2009, 27:3297-3302

157. Hirsh H, lliopoulos D, Tsichlis P, Stuh K: Metformin selectively targets cancer stem cells, and acts together with chemotherapy to block tumor growth and prolong remission. Cancer Res 2009, 69(19):7507-7511.

158. Scarpello J, Howlett H: Metformin therapy and clinical uses. Diabetes VasC Dis Res 2008, 5:157-167.

159. Rosand J, Friedberg J, Yang J: Fatal phenformin-associated lactic acidosis. Ann Intern Med 1997, 127:170.

160. Salpeter SR, Greyber E, Pasternak GA, Salpeter EE: Risk of fatal and nonfatal lactic acidosis with metformin use in type 2 diabetes mellitus. Cochrane Database Syst Rev 2010, 1:CD002967

161. Tahrani AA, Varghese Gl, Scarpello JH, Hanna FWF: Metformin, heart failure and lactic acidosis: is Metformin absolutely contraindicated? BMJ 2007, 355:508-512.

162. Lipska KJ, Bailey CJ, Inzucchi SE: Use of metformin in the setting of mild-to -moderate renal insufficiency. Diabetes Care 2011, 34(6):1431-1437.

163. Frid A, Sterner GN, Londahl M, et al: Novel assay of metformin levels in patients with type 2 diabetes mellitus and varying levels of renal function. Diabetes Care 2010, 33:1291-1293.

164. Metformin LS: Metformin: a review of its pharmacological properties and therapeutic use. Diabetes Metab 1979, 5:233-245.

165. Cusi K, DeFronzo RA: Metformin: a review of its metabolic effects. Diabetes Rev 1998, 6:89-131.

166. Bauman WA, Shaw S, Jayatilleke $E$, et al: Increased intake of calcium reverses vitamin B12 malabsorption induced by metformin. Diabetes Care 2000, 23:1227-1231

167. Callaghan TS, Hadden DR, Tomkin GH: Megaloblastic anemia due to vitamin B12 malaborsption associated with long-term metformin treatment. Br Med J 1980, 280:1214-1215.

168. Jager J, Kooy A, Lehert $P$, Wulffelé $M$, et al: Long term treatment with metformin in patients with type 2 diabetes and risk of vitamin B-12 deficiency: randomized placebo controlled trial. BMJ 2010, 340:c2181
169. Wei Ting RZ, Szeto CC, Chan M, Ma K, et al: Risk Factors of Vitamin B12 Deficiency in Patients Receiving Metformin. Arch Intern Med 2006, 166:1975-1979.

170. Klapholz L, Leitersdorf E, Weinrauch L: Leucocytoclastic vasculitis and pneumonitis induced by metformin. BMJ 1986, 293:483

171. Desilets DJ, Shorr AF, Moran KA, Holtzmuller KC: Cholestatic jaundice associated with the use of metformin. Am J Gastroenterol 2001, 96:2257-2258.

172. Kashyap AS, Kashyap S: Haemolytic anaemia due to metformin. Postgrad Med J 2000, 76:125-126.

173. Giugliano D, De Rosa N, Di Maro G, et al: Metformin improves glucose, lipid metabolism, and reduces blood pressure in hypertensive, obese women. Diabetes Care 1993, 16:1387-1390.

174. United Kingdom Prospective Diabetes Study (UKPDS) Group: Relative efficacy of randomly allocated diet, sulphonylurea, insulin, or metformin in patients with newly diagnosed non-insulin dependent diabetes followed for three years (UKPDS 13). BMJ 1995, 310:83-88.

175. Glucophage $\left.e^{(}\right)$and Glucophage XRproduct information. Bristol-Myers Squibb Company. 2003. Available at: www.drugs.com/pro/glucophage.html.

176. Haupt E, Knick B, Koschinsky T, Liebermeister H, Schneider J, Hirche H: Oral antidiabetic combination therapy with sulphonylureas and metformin. Diabete Metab 1991, 17:224-231.

177. Nathan DM, Buse JB, Davidson MB, et al: Management of hyperglycaemiain type 2 diabetes: a consensus algorithm for the initiation and adjustment of therapy: a consensus statement from the American Diabetes Association and the European Association for the Study of Diabetes. Diabetologia 2006, 49:1711-1721.

178. Grant P: The effects of high- and medium-dose metformin therapy on cardiovascular risk factors in patients with type 2 diabetes. Diabetes Care 1996, 19:64-66.

179. Garber AJ, Duncan TG, Goodman AM, Millus DJ, Rohlf JL: Efficacy of metformin in type 2 diabetes: results of a double-blind, placebocontrolled, dose-response trial. Am J Med 1997, 103:491-497.

180. Donahue S, Marathe P, Guld T, Meeker J: The phamacokinetics and pharmacodynamics of extended-release metformin tablets vs immediate-release metformin in subjects with type 2 diabetes. Diabetes 2002, 51(Suppl 2):A468.

181. Levy J, Cobas RA, Gomes MB: Assessment of efficacy and tolerability of oncedaily extended release metformin in patients with type 2 diabetes mellitus. Diabetol Metab Syndr 2010, 2:16.

182. Raz I, Delaet I, Goyvaerts H, et al: Safety and efficacy of novel extendedrelease formulation of metformin in patients with type 2 diabetes. Diabetes 2000, 49(Suppl 1):A363.

183. Donnelly LA, Morris AD, Pearson ER: Adherence in patients transferred from immediate release metformin to a sustained release formulation: a population-based study. Diabetes Obes Metab 2009, 11:338-342.

doi:10.1186/1758-5996-5-6

Cite this article as: Rojas and Gomes: Metformin: an old but still the best treatment for type 2 diabetes. Diabetology \& Metabolic Syndrome 2013 5:6.

\section{Submit your next manuscript to BioMed Central and take full advantage of:}

- Convenient online submission

- Thorough peer review

- No space constraints or color figure charges

- Immediate publication on acceptance

- Inclusion in PubMed, CAS, Scopus and Google Scholar

- Research which is freely available for redistribution 